\title{
TEACHING AND LEARNING MATHEMATICS THROUGH GAMES AND ACTIVITIES
}

\author{
Erika GYÖNGYÖSI WIERSUM \\ Comenius College Faculty, University of Miskolc, Sárospatak, Hungary, e-mail: gyerika@ hotmail.com
}

\begin{abstract}
In this paper we first present a theoretical approach to study mathematics teacher knowledge and conditions for developing it. Then some interesting activities and games are presented. As a result, this paper supplies teachers with information that may be useful in better understanding the nature of games, activities and their role in teaching and learning mathematics.

At the age of 10 pupils can concentrate less than 20 minutes during a lesson. However, a lesson in primary and secondary schools lasts for 45 minutes and 50 at universities. What a contradiction! To solve this problem we try to attract their attention with different techniques. As children and adults enjoy playing games we can teach and learn mathematics through games and activities. Experience reveals that games can be very productive learning activities. Are some games better than others? What educational benefits are there to be gained from games? How to integrate games in mathematics lessons? How to distinguish between 'activity' and 'game'? How to teach students specialising in electrical engineering and informatics using such an approach?
\end{abstract}

Keywords: teaching mathematics, learning mathematics, mathematical games, mathematical activities

\section{INTRODUCTION}

Mathematics education researchers have recently given an increasing attention to the knowledge and practices of mathematics teachers (see Bromme, 1994 [3]; Chevallard, 1997 [5]; Ball, 1997 [2]; Jaworski, 1998 [10]). In particular, the ways this knowledge and practice develops.

The aim of the paper is to study mathematics teacher knowledge and conditions for developing it in direct relation to teaching practice. We discuss the wider didactic perspectives of integrating games and activities into mathematics lessons.

What is a Mathematics Game? When considering the use of games for teaching and learning mathematics, educators should distinguish between an 'activity' and a 'game'. Gough, 1999 [8] states that "A 'game' needs to have two or more players, who take turns, each competing to achieve a 'winning' situation of some kind, each able to exercise some choice about how to move at any time through the playing". The key idea in this statement is that of 'choice'. In this sense, something like Snakes and Ladders is not a game because winning relies totally on chance. The players make no decisions, nor have to think further than counting. There is also no interaction between players - nothing that one player does affect other players' turns in any way.

Oldfield, 1991 [15] says that mathematical games are 'activities' which: involve a challenge, usually against one or more opponents; are governed by a set of rules and have a clear underlying structure; normally have a distinct finishing point; have specific mathematical cognitive objectives.

My purpose was to find generally useful mathematics games and activities for primary school students and teachers as I teach in a teacher training college. However, even in higher mathematics each topic can be made more interesting while students can play and they are motivated to think. Teachers task is to find the right games bringing abstract concepts closer to the real world. Also if teachers share their findings in papers then many other teacher can profit and improve their teaching methods to make teaching and learning more effective.

\section{BACKGROUND}

Teachers are alone as teachers in the preparation and conduct their teaching, and consequently a significant part of their observational didactic knowledge remains private. This leads to a question: "What can teachers learn together?" Generally, the concept of "professional learning community" (McLaughlin and Talbert, 2006 [13]) has become a main object of research and strategic intervention related to teacher development. A related question is that of the resources on which educators may draw in collective and individual efforts to develop their teaching (Guedet and Trouche, 2009 [9]; Winslow, 2011 [18]) - for example, teacher networks organised in technology based platforms may enable collective development of resources in institutions and even countries. These modalities of sharing and collectively develop resources appear indeed to be of increasing importance to many teachers. At the same time, we face the question about conditions that permit the sharing of didactic knowledge across and beyond individual schools, if that knowledge should really be conceived of as knowledge linked to the profession (rather than to a particular group or school (Stiegler and Hiebert, 1999 [17]; Cirade and Chevallard, 2010 [4]). Both questions are explained in this paper.

\section{MATHEMATICS GAMES AND ACTIVITIES}

Mathematics teaching and learning situations are characterised by the construction and sharing of practice and knowledge of a mathematical type. An organisation of practice and knowledge is called a mathematical organisation (Miyakawa and Winslow, 2012 [14]). Mathematical organisations are often identified and declared in broad terms like "arithmetic", "logic", "quadratics" etc. Such terms can be found in curricula and text books, but they do not suffice to describe the practice and knowledge enacted in a concrete situation (like a lesson etc.). Also, the teacher will have to develop a specific kind of practice and knowledge "that of teaching the mathematical organisation"; such organisations of practice and knowledge are called didactic 
organisations. Mathematical organisation developed in the classroom depends on the didactic organisation, in particular on what the teacher does and knows; and conversely, the didactic organisation is developed according to certain aims for the mathematical organisation, as well as with other restrictions in terms of pedagogy, time, material conditions, etc.

The following example represents the situation when you need to think deductively to solve the problem. It also improves the logical thinking of students which is a general aim in the curriculum. In this situation the mathematics organisation can be characterised by terms like "logic", "numbers", "arithmetic". The didactic organisation can be characterised by terms "game", "activities". The following game was invented by Petar Kenderov and Ivaylo Kortezov [11].

Example 3.1. Ann and John are playing the following game. First they both write the number 0 . Then they start playing in the following order. Ann is first and then John, Ann and John and etc. At each turning the player has to add a one-digit positive number to the number written last and then put down the sum. The player who first obtains a three-digit number wins. Is there a winning strategy for any of the players?

\section{The Winning Strategy is as follows:}

Supposing that it is the first player's turn and the first player has 90 to add to then he or she loses whatever number he or she puts down. In this case the second player wins as the sum written is more than 90 and less than 100 and it is his or her turn to add and to exceed 99 obtaining a three-digit number first. Thinking in this way the second player has the winning strategy if he or she adds numbers chosen by the first player to 10 or its multiples.

In the following game we represent the abstract concept of matrices in a form of a game. A game similar to the one mentioned in Example 3.2 was invented by Attila Máder [12]. I generalised his problem and translated it into English in this paper.

Example 3.2. Two players play the following game. They are given a bar of chocolate $m \times n$ which has $m$ rows and $n$ columns. The players have to break up the bar along the lines representing the rows and columns. The player who can break off the last piece of the chocolate bar along one of the lines last wins. Which player has the winning strategy?

It depends on $m$ and $n$. If $m \times n$ is an even number then the game is over in the $(m \times n-1)^{\text {th }}$ step. As $m \times n-1$ is an odd number the first player wins. If $m \times n$ is an odd number then the second player wins.

The two games mentioned in the first two examples can be programmed and with the help of computers students are challenged to find the winning strategy playing. While playing and guessing they can try many possibilities in a relatively short time as computers carry out calculations fast. After finding the main patterns they can get closer and closer to the solution and their problem solving strategies and logical thinking is improving during the games. Also it is very important to find balance between the traditional pen and paper methods and using technology while teaching and learning mathematics.

During my teaching practice at Comenius College belonging to the University of Miskolc, where we also train primary school teachers I often experienced that most students always use calculators to calculate. However, when they were asked to calculate without any help of calculators they often calculated incorrectly and some of them were not capable to carry out simple operations. Therefore they obviously need to practice their calculation skill which is substantial as they are going to teach how to calculate in primary schools. In order to make tedious calculations less boring I found some mathematical activities to make calculations more enjoyable. Surprisingly while I was studying French I found the following example in a French textbook: Learn French Easily and Fast written by Ferenc Somorjai [16] on page 284. I translated the French version into English.

Example 3.3. If you carry out the following operations correctly and tell me the final result I can tell you how old you are and the number you live at.

1. Put down the number where you live at;

2. Double this number;

3. Add 5 to it;

4. Multiply it by 50 ;

5. Add the number of your age (in years);

6. Then add 365 to this number (a number of days of a year except for a leap year);

\section{Subtract 615 from the result.}

The solution is: the final two digits of the result represent your age and the digits in front of them represent the number where you live at. If your calculations were correct. You can find the mathematics explanation to this solution in the background.

The following example was found in an old Hungarian textbook for primary school pupils: Calculate edited by Béla Fülöp [7].

Example 3.4. Think of a number and double it. Then add 1 to it and multiply the number obtained in this way by 5. Tell me the final result and I find out which number you thought of.

If students can find out the mathematics explanation then their logical thinking is also improved.

This explanation is simply as follows: the number you think of is $x$. According to the instructions you need to carry out the following operations: $(2 x+1) \times 5=10 x+5$.

Hence if I subtract 5 from the final result and divide it by 10 I obtain the number you thought of.

What are the Benefits of Using Games? The advantages of using games in Mathematics were summarised by Davies, 1995 [6]: 
- Meaningful situations - for the application of mathematical skills are created by games;

- Motivation - children freely choose to participate and enjoy playing;

- Positive attitude - games provide opportunities for building self-concept and developing positive attitudes towards mathematics, through reducing the fear of failure and error;

- Increased learning - in comparison to more formal activities, greater learning can occur through games due to the increased interaction between children, opportunities to test intuitive ideas and problem solving strategies;

- Different levels - games can allow children to operate at different levels of thinking and to learn from each other. In a group of children playing a game, one child might be encountering a concept for the first time, another may be developing his/her understanding of the concept, a third integrating previously learned concepts;

- Assessment - children's thinking often becomes apparent through the actions and decisions they make during a game, so the teacher has the opportunity to carry out diagnosis and assessment of learning in a non-threatening situation;

- Home and school - games provide 'hands-on' interactive tasks for both school and home;

- Independence - children can work independently of the teacher. The rules of the game and the children's motivation usually keep them on task.

\section{Hints for Successful Classroom Games}

These tips come from Aldridge \& Badham, 1993 [1]:

- Make sure the game matches the mathematical objective;

- Use games for specific purposes, not just time-fillers;

- Keep the number of players from two to four, so that turns come around quickly;

- The game should have enough of an element of chance so that it allows weaker students to feel that they have a chance of winning.

- Keep the game completion time short;

- Use five or six 'basic' game structures so the children become familiar with the rules - vary the mathematics rather than the rules;

- Send an established game home with a child for homework;

- Invite children to create their own board games or variations of known games.

\section{FINDINGS}

Through games and mathematics activities with the others, students build a sense of mathematical values, and based on that they act by constructing and modifying their thinking. The establishment of regular and institutionally share didactic infrastructure may be a main key to enhance the professional knowledge of teachers. Private practices rarely achieve high professional status and the knowledge of the practitioner disappears with her. That is why teaching methods and development of didactic infrastructures like "teaching and learning through games and activities" are of crucial importance to the teaching profession. I have integrated these games and mathematics activities mentioned above into my teaching practice. As a feedback most of my students handed in a list (minimum 10 examples) of games and activities with solutions. They enthusiastically spent hours to find these examples on the internet and in books and I was very impressed by them.

Seeing how interested and keen students were I decided to programme games in the first two examples with the help of my college László Bednarik who is qualified as an engineer and computer specialist working as an assistant lecturer at Comenius College belonging to the University of Miskolc preparing for completing his PhD studies in computer sciences. Presently we are working on this joint project.

Each student specialising in electrical engineering and informatics must learn mathematics. Therefore if they are taught with methods bringing abstract mathematics concepts closer to their understanding they can be more successful in their field.

One of this methods is to ask them to programme games and another is to find out more games. In this way their creativity and logical thinking and problem solving techniques could considerably improve.

Another new method I integrated into my teaching was observed in Copenhagen, Denmark. I carried out research work in Didactics of Mathematics for 4 months with Professor Carl Winslow at the University of Copenhagen in 2010 and I was surprised to see the way they conducted analysis seminars. Each student had his own computer and the teacher wrote a list of problems on the blackboard. Then students worked in groups to find solutions for the problems. The teacher was walking around groups of students and he helped their work only if it was necessary. In this way students worked together and the teacher's role was only to support their work and then discuss their solutions. Students also had homework to work on projects containing several mathematical problems and experimenting with mathematics computer software (they used mostly MATHEMATICA) were allowed. They could solve problems individually or in their group, however, each of their solution had to be different from the other members of the group. Students have become more self confident and cooperative and not just passive receiver of the information. 


\section{ACKNOWLEDGEMENT}

The author thanks the members of the organizing committee of the CEEPUS Summer School 2012 - Nature in Mathematics (Košice - High Tatra Mountains), particularly to Štefan Berežný. Many thanks to Péter Körtesi from the University of Miskolc for his invitation to take part in this summer school.

\section{REFERENCES}

[1] ALDRIDGE, S. - BADHAM, V.: Beyond Just a Game, Pamphlet Number 21, Primary Mathematics Association, 1993.

[2] BALL, D.: Developing Mathematics Reform: What Don't We Know about Teacher Learning - But Would Make Good Working Hypotheses, In S. Friel \& G. Bright (Eds.), Reflecting on our work: NSF teacher enhancement in K-5 mathematics (pp. 77-111). Lanham, NY: University Press of America, 1997.

[3] BROMME, R.: Beyond Subject Matter: a Psychological Topology of Teachers' Professional Knowledge, In: R. Biehler et al. (Eds.), Didactics of Mathematics as a scientific discipline (pp. 73-78). Dordrecht: Kluwer, 1994.

[4] CIRADE, C. - CHEVALLARD, Y.: Les resources manquantes comme problème professionnel, In G. Gueudet \& L. Trouche (Eds.), Ressources vives. Le travail documentaire des professeurs en mathématiques, pp. 41-55, Rennes: Presses Universitaires de Rennes, 2010.

[5] CHEVALLARD, Y:: Familière et problématique, la figure du professeur, Recherches en Didactique des Mathématiques, 17 (3), 17-54, 1997.

[6] DAVIES, B.: The Role of Games in Mathematics, Square One, Vol. 5, No. 2, 1995.

[7] FÜLÖP, B. ed.: Számítsd ki, [Calculate], textbook for primary school pupils, Tankönyvkiadó, [National texbook publisher], Budapest, 1950.

[8] GOUGH, J.: Playing Mathematical Games: When Is a Game Not a Game?, Australian Primary Mathematics Classroom, Vol. 4, No. 2, 1999.

[9] GUEDET, G. - TROUCHE, L.: Towards new documentation systems for teachers?, Educational Studies in Mathematics, 71 (3), 199-218, 2009.

[10] JAWORSKI, B.: Mathematics Teacher Research: Process, Practice and the Development of Teaching, Journal of Mathematics Teacher Education, 1 (1), 3$31,1998$.

[11] KENDEROV, P. - KORTEZOV, I.: MATHEU - Identification, Motivation and Support of Mathematical
Talents in European Schools, Manual, Volume 2, Gregory Makrides, INTERCOLLEGE, Cyprus (Eds.), Published by MATH.EU Project, 2011.

[12] MÁDER, A.: Elemi Matematika Feladatok, [Elementary Mathematics Problems], www.math.u-szeged. hu/ madera/el37jatfa.pdf. 2008.

[13] MC LAUGHLIN, M. W. - TALBERT, J. E.: Building School Based Teacher Learning Communities: Professional Strategies to Improve Student Achievement, New York: Teachers' College Press, 2006.

[14] MYAKAWA, T. - WINSLOW, C.: Developing Mathematics Teacher Knowledge: The Paradidactic Infrastructure of "Open Lesson" in Japan, Under publish.

[15] OLDFIELD, B.: Games in the Learning of Mathematics, Mathematics in Schools, January, 1991.

[16] SOMORJAI, F.: Tanuljunk könnyen gyorsan franciául, [Learn French Easily and Fast], textbook, Publisher G \& A, 1997.

[17] STIEGLER, J. - HIEBERT, J.: The Teaching Gap, New York: The Free Press, 1999.

[18] WINSLOW, C.: A Comparative Perspective on Teacher Collaboration: the Cases of Lesson Study in Japan and of Multidisciplinary Teaching in Denmark, In G. Gueudet, B. Pepin and L. Trouche (Eds.), Mathematics curriculum material and teacher documentation: from textbooks to shared living resources, pp. 291-304, New York: Springer, 2011.

Received July 23, 2012, accepted September 26, 2012

\section{BIOGRAPHY}

Erika Gyöngyösi was born on 5.10.1973. In 1999 she graduated (MSc) with distinction at the department of Mathematics at Kossuth Lajos University in Debrecen, Hungary. She defended his $\mathrm{PhD}$ with summa cum laude qualification in recognition of her proficiency in the field of Mathematics and Computer Sciences in 2004 at the University of Debrecen; her thesis title was "Computer assisted teaching of mathematics: potentials and possible dangers". Between 2004 and 2011 she was working as a tutor and since 2012 she is working as an assistant lecturer at Comenius College Faculty of Miskolc University. Her scientific research is focusing on teaching and learning method in order to make mathematics learning more effective. In addition, she also investigates questions related with integrating computers into teaching and learning mathematics in primary secondary and advanced levels. She is also very interested in how to make lectures in English for foreigners more interesting through games and mathematics activities. 